\title{
Most regions of mouse epididymis are able to phagocytose immature germ cells
}

\author{
P Ramos-Ibeas, E Pericuesta, R Fernández-González, M A Ramírez and A Gutierrez-Adan \\ Department of Animal Reproduction, INIA, Avenida Puerta de Hierro 12, Local 10, Madrid 28040, Spain \\ Correspondence should be addressed to P Ramos-Ibeas; Email: priscilaramosibeas@gmail.com
}

\begin{abstract}
The role of the epididymis as a quality control organ in preventing infertile gametes entering the ejaculate has been extensively explored, and it has been suggested that a specific region of mammalian epididymis is able to phagocytose abnormal germ cells. This study examines whether the epithelium of certain zones of the mouse epididymis can act as a selection barrier by removing immature germ cells from the lumen by phagocytosis. To detect the presence of immature germ cells in the epididymis, we generated transgenic mice expressing enhanced green fluorescent protein under the deleted in azoospermia-like ( $m$ Dazl) promoter to easily identify immature germ cells under fluorescence microscopy. Using this technique, we observed that during the first stage of spermatogenesis in prepuberal mice, a wave of immature germ cells is released into the epididymis and that the immature epididymis is not able to react to this abnormal situation. By contrast, when immature germ cells were artificially released into the epididymis in adult mice, a phagocytic response was observed. Phagosomes appeared inside principal cells of the epididymal epithelium and were observed to contain immature germ cells at different degradation stages in different zones of the epididymis, following the main wave of immature germ cells. In this paper, we describe how the epididymal epithelium controls sperm quality by clearing immature germ cells in response to their artificially induced massive shedding into the epididymal lumen. Our observations indicate that this phenomenon is not restricted to a given epididymis region and that phagocytic capacity is gradually acquired during epididymal development.
\end{abstract}

Reproduction (2013) 146 481-489

\section{Introduction}

Successful mammalian fertilization is dependent on the presence of intact functional gametes such that quality control is required during and after gametogenesis. Female gamete selection occurs in the ovaries, and atretic follicles are eliminated in such a way that only competent oocytes are released. By contrast, male gametes acquire their fertilizing capacity during epididymal transit. The epididymis constitutes an appropriate microenvironment that allows immature spermatozoa produced in the testicle to become motile. Its functions include sperm sustenance, transport, and storage, as well as metabolite absorption, secretion, synthesis, and catabolism (Jones 2004, Quintar et al. 2011).

A possible additional role of the epididymis as a quality control organ has been long disputed. The hypothesis was proposed in the 1930s, when Simone \& Young (1931) observed the removal of non-ejaculated spermatozoa by the epididymis. Later on, many authors accepted this role and proposed different mechanisms for sperm removal ranging from their dissolution in the duct lumen (Waldschmidt \& Kinzler 1964) to spermiophagy by macrophages (Phadke 1964, Alexander 1972) or by principal cells in the epididymal epithelium
(Roussel et al. 1967, Paufler \& Foote 1969, Crabo et al. 1971, Tingari \& Lake 1972). Although there was extensive histological and ultrastructural evidence to suggest that the phagocytosis of spermatozoa was a rare event in the normal epithelium (Amann 1970, Amann et al. 1974), a ubiquitin-dependent sperm quality control mechanism accomplished by phagocytosis was later described by Sutovsky et al. (2001). Many authors have refuted this mechanism (Cooper et al. 2002, Jones 2004), and recent evidence suggests that principal cells in the epididymal epithelium in some regions of the rat epididymis are able to phagocytose immature germ cells (Quintar et al. 2011). The conditions in which the epididymis is able to eliminate defective or immature germ cells remain to be clarified.

This study was designed to determine whether the epithelium of different zones of the mouse epididymis acts as a selection barrier for abnormal sperm cells by removing immature cells from the lumen by phagocytosis. To examine the transit of immature germ cells through the different regions of the mouse epididymis, a transgenic mouse model expressing a reporter gene under the deleted in azoospermia-like ( $m D a z l)$ promoter was generated. The autosomal Dazl gene is expressed throughout germ cell development, from embryonic 
primordial germ cells to mature gametes in adults (Reijo et al. 2000) and across both non-mammalian and mammalian species (Yen 2004).

In this animal model, enhanced green fluorescent protein (EGFP) is specifically expressed under $\mathrm{mDazl}$ control in spermatogonia, spermatocytes, and spermatids. By fluorescence microscopy, we were able to observe the presence of germ cells released from the testicles throughout the epididymis. The main aim of our study was to examine the behavior of mice epididymal epithelium in response to the massive influx of immature germ cells shed into the luminal fluid.

\section{Materials and methods}

\section{Culture and transformation of embryonic stem cells}

Using previously described methods, an XY embryonic stem cell (ESC) line was derived in our laboratory from fertilized embryos in hybrid female mice (C57BL/6 $\times$ DBA/2) (Pericuesta et al. 2006). The ESC line was initially checked for pluripotency based on the expression of molecular markers specific for ESCs (Ramirez et al. 2006) and its ability to successfully produce chimeras showing germline transmission. Karyotype analysis was performed as described previously (Ramirez et al. 2007).

The ESC line was maintained in mitomycin-C treated (Sigma-Aldrich Corporation) mouse embryonic fibroblast cells on $0.1 \%$ gelatin-coated tissue plates and cultured in ESC medium composed of DMEM (DMEM plus $4500 \mathrm{mg} / \mathrm{l}$ glucose, glutaMAX, and pyruvate; Invitrogen) supplemented with $20 \%$ FBS (PAA Laboratories, Cölbe, Germany), 2 mM glutamine, $1 \mathrm{mM}$ MEM nonessential amino acids solution, $1 \mathrm{mM} \beta$-mercaptoethanol, $1000 \mathrm{U} / \mathrm{ml}$ leukemia inhibitory factor, and an antibiotic mixture containing $100 \mathrm{U} / \mathrm{ml}$ penicillin and $100 \mathrm{mg} / \mathrm{ml}$ streptomycin.

ESCs were transformed by transfecting the linearized Dazl-eGFP transgene (Nicholas et al. 2009) by electroporation as follows: $10 \mu \mathrm{g}$ of the linearized Dazl-eGFP construct were electroporated into $3 \times 10^{6}$ cells using a Multiporator (Eppendorf, Hamburg, Germany) and a pulse of $300 \mathrm{~V}$, $500 \mu \mathrm{s}$. Cells were allowed to recover for $24 \mathrm{~h}$ before Geneticin 418 (G418) was added to a final concentration of $150 \mu \mathrm{g} / \mathrm{ml}$. Cellular clones were selected by geneticin resistance over 7 days and screened for GFP expression under fluorescence microscopy. DNA from the transformed ESCs was processed for PCR analysis to confirm transgene integration using standard protocols (Ramirez et al. 2007).

\section{Production of Dazl-GFP transgenic mice}

For Dazl-GFP transgenic mice production, eight-cell stage embryos from CD1 mice were used for ESC injection using piezo equipment to produce healthy, full germline-competent mice from hybrid ESCs (Ramirez et al. 2009). Mice were kept on a $14 \mathrm{~h}$ light:10 h darkness cycle. CD1 female mice (8- to 10-weekold) were superovulated by i.p. injection of $7.5 \mathrm{IU}$ of equine chorionic gonadotropin (pregnant mares serum gonadotrophin; Intervet, Boxmeer, Holland) followed $48 \mathrm{~h}$ later by $5 \mathrm{IU}$ of human chorionic gonadotropin (hCG; Lepori, Farma-Lepori,
Barcelona, Spain). On the day of hCG injection, female mice were paired with male mice of the same strain to allow mating. Eight-cell embryos were collected 2.5 days post-coitum (dpc) as described previously (Miranda et al. 2011).

A single ESC was injected into eight-cell stage CD1 mice embryos using Eppendorf micromanipulators (Eppendorf TransferMan NK 2). Embryos were cultured for $24 \mathrm{~h}$ in potassium simplex optimization medium supplemented with amino acids, and 4\% ESC medium droplets overlaid with mineral oil in a humidified atmosphere of $5 \% \mathrm{CO}_{2}$ at $37^{\circ} \mathrm{C}$. After culture, blastocysts and compacted morulae were transferred into the left uterus of a $2.5 \mathrm{dpc}$ CD1 female (Ramirez et al. 2009). To generate chimeras and FO ES-derived mice, pregnancies were continued to term. DNA from newborn mice was then processed for PCR analysis to identify EGFP integration using standard protocols.

All the animals were kept in an animal house and handled using procedures and protocols approved by the Animal Care and Ethics Committee (CEEA 2009/009) of the Instituto Nacional de Investigación y Tecnología Agraria y Alimentaria (INIA, Madrid) conducted in accordance with European Union (Directive 86/609/EEC) and Spanish (BOE 252/34367-91, 2005) legislation.

\section{Colchicine administration and tissue collection for light microscopy}

Male Dazl-eGFP transgenic mice were anesthetized with isoflurane (Isoba vet, Schering-Plough Animal Health, Middlesex, UK) and the testes were exposed via an abdominal incision. A $50 \mu \mathrm{l}$ bolus of a solution containing $10 \mu \mathrm{g} / \mathrm{ml}$ colchicine (Karyomax Colcemid, Gibco) plus Fast Green FCF (Sigma-Aldrich) to check the correct infusion of the solution were injected into the rete testis using a 30-gauge hypodermic needle. Non-injected contralateral testes were used as negative controls. Animals were killed by cervical dislocation, the efferent ducts and epididymides were dissected and the presence or absence of immature germ cells was determined under fluorescence stereoscopy (Nikon SMZ1500). Next, the efferent ducts and epididymides were fixed in Bouin's fluid for $6 \mathrm{~h}$, this fluid was replaced with $70 \%$ ethanol and the tissue was then paraffin embedded, sectioned ( $5 \mu \mathrm{m})$, and analyzed.

\section{Hematoxylin staining}

Slides were deparaffinized by incubating four times for $4 \mathrm{~min}$ in xylene and rehydrated $(100,96$, and $70 \%$ ethanol, water; 4 min each). The slides were then exposed to hematoxylin for $30 \mathrm{~s}$ and rinsed in tap water for $5 \mathrm{~min}$. Finally, the slides were dehydrated by conducting two 20-s incubations in increasing concentrations of ethanol (96 and 100\%) and four further 20-s incubations in xylene. Coverslips were mounted using Vectamount mounting medium (H-5501, Vector, Burlingame, CA, USA) and observed by bright field microscopy (Nikon OPTISHOT-2).

\section{Immunohistochemistry}

Slides were deparaffinized and rehydrated as described earlier, and antigens retrieved by heating the slides immersed in trisodium citrate buffer $10 \mathrm{mM}$ for $3 \mathrm{~min}$ in a pressure cooker. 
Next, endogen peroxidase was blocked in $0.3 \%$ hydrogen peroxide (Sigma-Aldrich) for $30 \mathrm{~min}$ at room temperature, and the tissue sections were permeabilized with PBS- $0.1 \%$ Tween 20 (Merck-Schuchardt) for $5 \mathrm{~min}$, blocked in 10\% normal goat serum (S-1000, Vector) for $30 \mathrm{~min}$, and treated with the avidin/biotin blocking kit (SP-2001, Vector). The slides were then incubated overnight at $4{ }^{\circ} \mathrm{C}$ with rabbit anti-GFP antibody diluted 1:500 (GTX 20290, Genetex, San Antonio, TX, USA). This was followed by incubation for $1 \mathrm{~h}$ at room temperature with a 1:300 dilution of biotinylated goat antirabbit IgG secondary antibody (BA-1000, Vector), $30 \mathrm{~min}$ at room temperature with the Vectastain Elite $A B C$ Kit (Vector), and $10 \mathrm{~min}$ at room temperature with the Vector NovaRED Substrate Kit (SK-4800, Vector). Coverslips were mounted using Vectamount mounting medium (H-5501, Vector) and observed by bright field microscopy (Nikon OPTISHOT-2).

\section{Tissue collection and preparation for transmission electron microscopy}

Epididymides were diced into small pieces about $2 \mathrm{~mm}$ thick and fixed in $4 \%$ paraformaldehyde - $2.5 \%$ glutaraldehyde in PBS for $5 \mathrm{~h}$. The samples were then treated with $1 \% \mathrm{OsO}_{4}-$ $1.5 \%$ potassium ferricyanide for $1 \mathrm{~h}$, dehydrated $(30,50,70,80$, 90, 95, and $100 \%$ acetone, water; $15 \mathrm{~min}$ each) and resin infiltrated (1-h $3: 1$ and 1:1 acetone:resin incubations, a 2-h $1: 3$ acetone:resin incubation and overnight incubation in $100 \%$ resin). Finally, the samples were embedded in resin and polymerized at $70^{\circ} \mathrm{C}$ for $48 \mathrm{~h}$. Thin sections were cut with a diamond knife and examined in a JEOL JEM 1010 transmission electron microscope at the ICTS Centro Nacional de Microscopía Electrónica (Madrid, Spain).

\section{Experimental design}

The study was performed in three steps as follows:

i) To examine the spontaneous release of immature germ cells into the immature epididymis, prepuberal Dazl-EGFP mice were killed at the ages of 10, 15, 18, 21, 26, 30, and 35 days.

ii) To determine the response of the mature epididymis to the massive release of immature germ cells, colchicine was administered to 5-month-old Dazl-EGFP mice, which were killed daily from 1 to 8 days after the colchicine injection.

iii) To examine the effect of the artificial release of immature germ cells into the immature epididymis in prepuberal mice, colchicine was administered to 23-day-old Dazl-EGFP mice, which were killed daily from 1 to 8 days after the colchicine injection.

\section{Results}

\section{Production of mDazl-EGFP transgenic mice}

Transgenic mice expressing EGFP under the deleted in azoospermia-like ( $m D a z l)$ promoter were generated to detect the presence of immature germ cells throughout the epididymis. The promoter activity of a $1.7-\mathrm{kb}$ sequence located upstream of the mouse Dazl translation start site has been described as sufficient to drive robust germ cell-specific expression (Nicholas et al. 2009). One mDazl-EGFP-transfected ESC was injected into 66 eight-cell stage embryos of CD1 mice. Fifty-nine developed into blastocysts and were transferred to pseudopregnant CD1 females. Pregnancies were allowed to run to term and 18 newborn mice were obtained. The efficiency of the generation of F0 ESC mice was quantified as the percentage ESC coat color contribution and germline transmission. Four chimeric mice with more than $75 \%$ ESC coat color were produced. In our transgenic mice, mDazl-EGFP expression within the testicle was restricted to germ cells and not detected in interstitial Leydig cells or Sertoli cells lining the basement membrane of the seminiferous tubules. The transgene was specifically expressed in spermatogonia, spermatocytes, and round and elongating spermatids, although not in spermatozoa (Fig. 1). Thereby, immature germ cells could be easily identified under fluorescence microscopy and were visible through the epididymal tubules.

\section{Spontaneous release of immature germ cells in prepuberal mice}

To explore the onset of spermatogenesis and epididymal function during development, prepuberal mDazl-EGFP mice were sequentially killed at different ages and
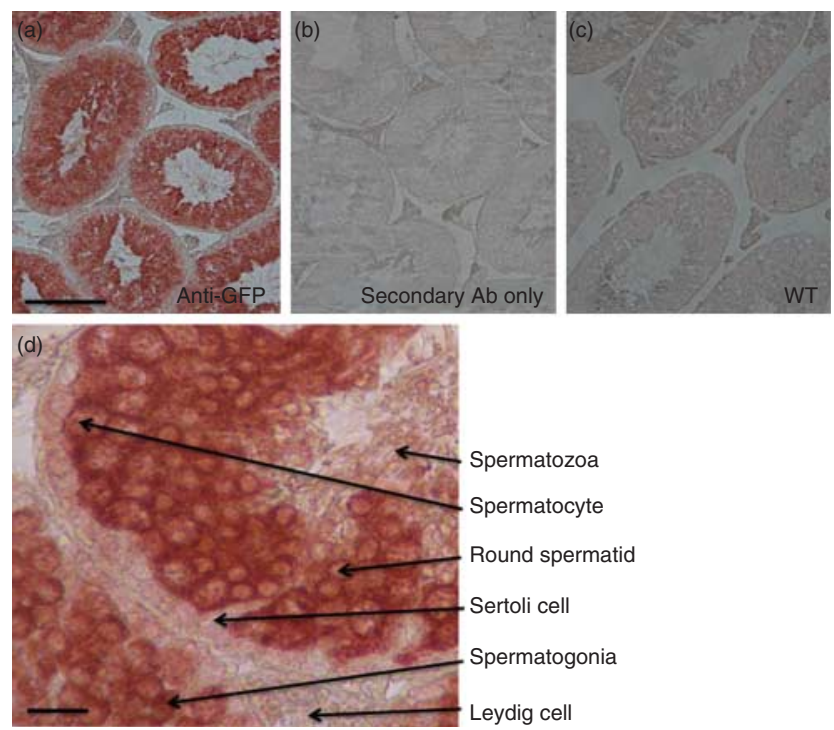

Figure 1 Germ cell-specific mDazl-EGFP expression. (a) Immunohistochemical staining of an adult testis section of a transgenic mDazl-EGFP mouse using anti-GFP antibody; (b) control staining of an adult testis section of a transgenic mDazl-EGFP mouse using the secondary antibody alone; and (c) staining of an adult testis section of a WT mouse using anti-GFP antibody, bar $=100 \mu \mathrm{m}$. (d) Magnification of a seminiferous tubule in an adult testis section of a transgenic $m$ Dazl-EGFP mouse, bar $=20 \mu \mathrm{m}$. 

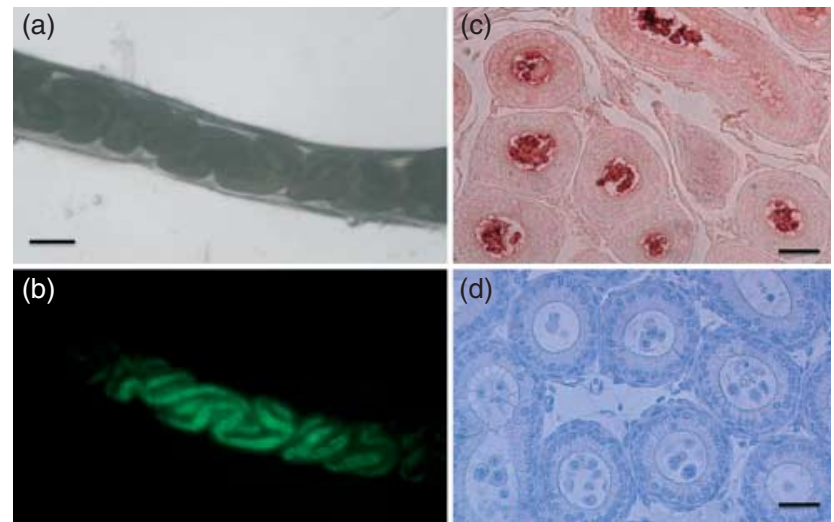

Figure 2 Spontaneous immature germ cell release in the prepuberal epididymis. (a) Bright field and (b) fluorescent stereoscopy pictures of corpus epididymis obtained from a 21-day-old mouse, bar $=200 \mu \mathrm{m}$. (c) Immunohistochemical labeling using anti-GFP antibody of the same epididymis, bar $=50 \mu \mathrm{m}$. (d) Hematoxylin staining showing a lack of phagocytosis in prepuberal epididymis after colchicine-induced massive release of immature germ cells, bar $=50 \mu \mathrm{m}$.

epididymides collected and examined by fluorescence stereoscopy. At the ages 10 and 15 days, no fluorescence was detected. By contrast, a wave of fluorescent cells was observed through the corpus epididymis in 18-dayold tissue. These fluorescent cells were more evident at 21 days in all epididymal regions (Fig. $2 \mathrm{a}$ and b). Up until day 30, fluorescence diminished in the epididymis caput and corpus yet was still intense in the caudal region. At 35 days, sperm reached the epididymis and was visible through epididymal tubules, but no immature fluorescent cells were observed.

To confirm the identity and location of fluorescent cells and examine the epididymal response to immature cells, epididymal sections were stained with hematoxylin and immunostained to detect EGFP expression. At the prepuberal ages 10 and 15 days, epididymal tubules showed a narrow lumen enclosed by an immature epididymal epithelium, and no GFP-positive cells were detected. By 21 days, the tubular lumen appeared larger and contained immunostained round cells in some tubule sections in the caput, corpus, and cauda epididymis and also in the ductus deferens (Fig. 2c). EGFP-positive cells persisted in the lumen in all epididymal regions at 26 and 30 days. Finally, in 35-day-old mice, the tubular lumen appeared filled with spermatozoa, although some small, round immature germ cells (possibly spermatids) staining positive for EGFP could be observed within the sperm, mainly in the cauda epididymis and ductus deferens. No signs of phagocytosis were observed in any epididymal region at any prepuberal age.

\section{Response of the mature epididymis to the massive release of immature germ cells}

To examine the response of the mature epididymis to the massive release of immature germ cells, the testicles of adult transgenic mice were injected with colchicine, a microtubule-depolymerizing agent that severely modifies the architecture of the seminiferous tubules. The contralateral testicles were not injected and epididymides were used as negative controls. Twenty-four hours post-colchicine administration, injected testicles were fixed, sectioned, and immunostained to examine the effects of colchicine. Severe alterations of the seminiferous tubule epithelium were observed along with GFPpositive immature germ cells detached from the tubular lumens. The mice were killed daily from 1 to 8 days postcolchicine administration and epididymides were examined by fluorescent stereoscopy. Fluorescent immature germ cells were present in the caput epididymis $24 \mathrm{~h}$ after colchicine administration and progressed through the corpus and cauda to abandon the epididymis 6 days
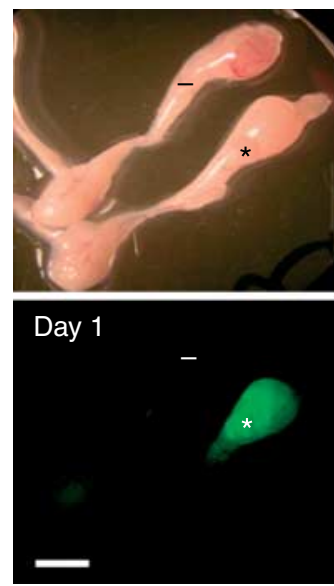
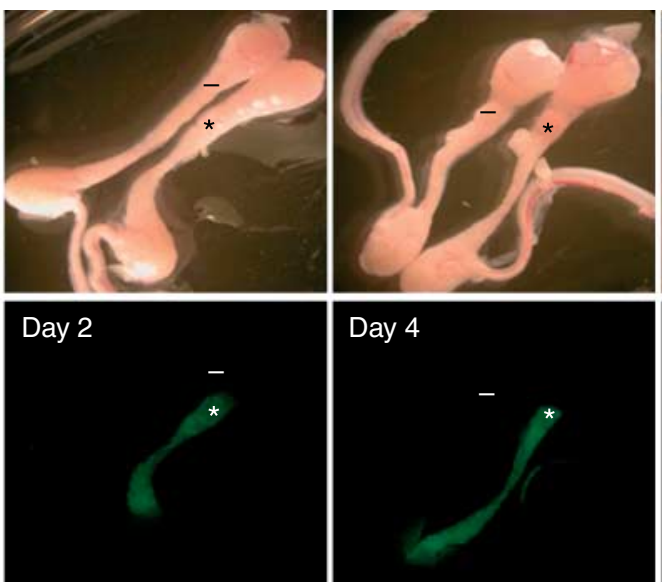

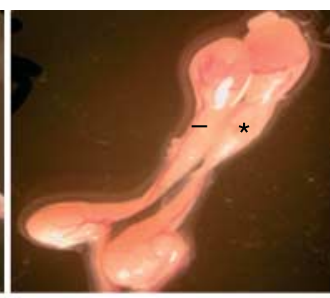

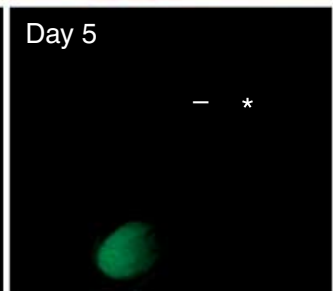
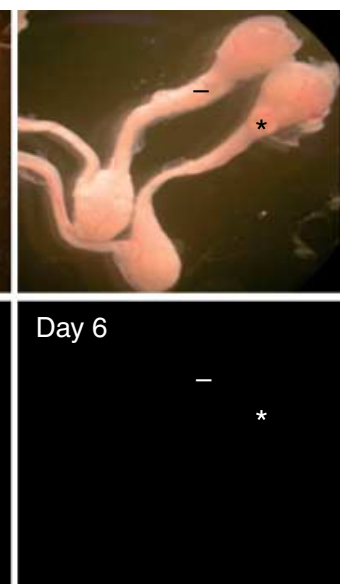

Figure 3 Transit of immature germ cells through the adult epididymis after colchicine administration. Bright field and fluorescent stereoscopy pictures. Fluorescent immature germ cells were present in the caput epididymis $24 \mathrm{~h}$ after colchicine administration and progressed through the corpus and cauda to abandon the epididymis 6 days after colchicine administration $\left(^{*}\right)$. No fluorescent cells were observed in non-colchicines-injected epididymides $(-)$, bar $=500 \mu \mathrm{m}$. 

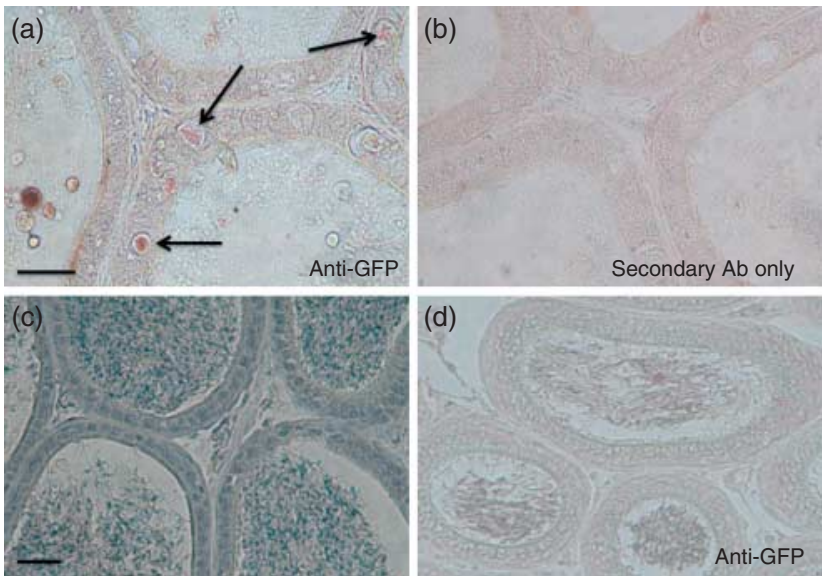

Figure 4 Anti-GFP immunohistochemistry showing phagosomes containing EGFP-positive immature germ cells in the epithelial cells of the epididymis. (a) Staining with the anti-GFP antibody and (b) control staining using the secondary antibody alone, bar $=20 \mu \mathrm{m}$. (c) No immature germ cells and phagosomes were observed in non-colchicines-injected epididymides. Hematoxylin staining, (d) anti-GFP immunohistochemistry, bar $=50 \mu \mathrm{m}$.

after colchicine administration. No fluorescent cells were observed in non-injected epididymides (Fig. 3).

Efferent ducts and epididymis sections were stained with hematoxylin and analyzed by bright light microscopy. No phagocytosis was detected in efferent ducts. No immature germ cells or phagosomes were observed in non-treated epididymides (Fig. 4c and d). Conversely, in tissue sections from colchicine-injected mice, phagosomes were observed inside the principal cells of the epididymal epithelium containing immature germ cells showing different extents of degradation (Fig. 4a and b). This phagocytosis was observed throughout the epididymis following the main wave of fluorescent immature cells.

According to Turner et al., each epididymal region can be divided into segments containing lobules of coiled tubules bordered by connective tissue septa. In mice, the caput, corpus, and cauda epididymides are divided into four, one, and two segments respectively designated epididymal segments 1-7 (Turner et al. 2003). At 4 days post-colchicine administration, when immature cells had reached the corpus epididymis as observed by fluorescence stereoscopy, phagocytosis was first detected in segments 2, 3, and 4 in the caput epididymis (Fig. 5). By transmission electron microscopy, we were able to observe that epithelial cells contained ingested material at different degradation stages, giving rise to different-sized vacuoles. Often, several phagosomes were observed within the same epithelial cell causing the displacement of organelles by mechanical compression (Fig. 6a). Similarly, various immature germ cells in degradation were observed within the same vacuole. Different extents of immature germ cell degradation were observed within the phagosomes
(Fig. 6b, c, d, e and f), ranging from non-degraded immature germ cells (Fig. 6c) to laminar structures or products of the digestion of cell membranes (Fig. 6b). Remains of the nuclei of more mature spermatogenic cells were also found (Fig. 6f). However, we observed no spermatozoa in the process of phagocytosis.

At 5 days post-colchicine administration, once the immature cells had arrived at the cauda epididymis, phagocytosis was observed in certain areas within the corpus epididymis (segment 5). On day 6 postcolchicine administration, the main wave of immature cells had abandoned the epididymis as no fluorescence was detected. However, a number of immature cells were present in some tubules and phagocytosis was observed in the corpus (segment 5) and cauda (segments 6 and 7) epididymis. Phagosomes in the corpus and cauda epididymis were larger than phagosomes in the caput epididymis and contained complete immature germ cells or appeared empty. Epithelial cells involved in phagocytosis showed an abnormal appearance due to compression by the larger phagosomes (Fig. 5).

The intensity of phagocytosis was quantified as the number of phagosomes observed per tubule in the
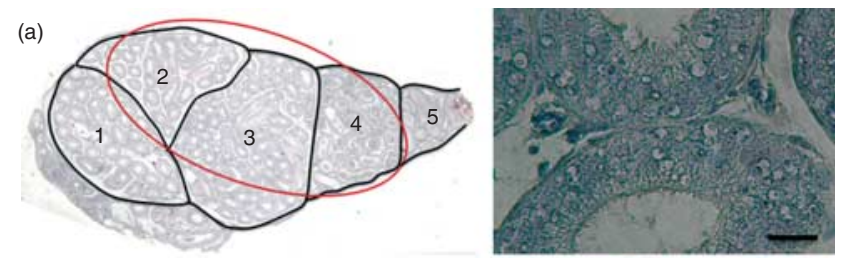

(b)
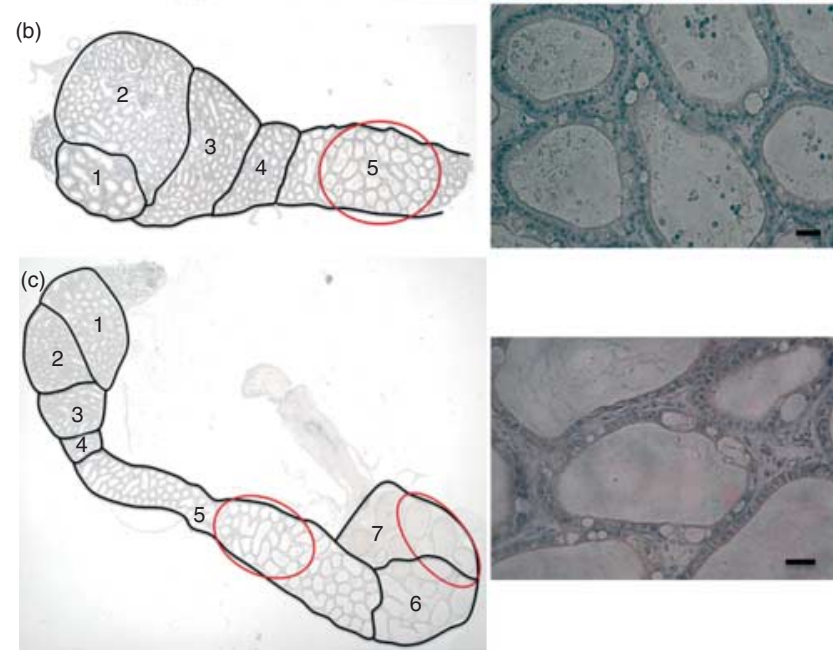

Figure 5 Phagocytosis of immature germ cells in adult epididymides. Hematoxylin staining. (a) Phagosomes localized in epididymal segments 2, 3, and 4 (caput epididymis) at 4 days post-colchicine administration. (b) Phagosomes localized epididymal segment 5 (corpus epididymis) at 5 days post-colchicine administration. (c) Phagosomes localized in epididymal segments 5, 6, and 7 (corpus and cauda epididymis) at 6 days post-colchicine administration. Epididymis segmentation according to Turner et al. (2003). Microscopy pictures: bars $=20 \mu \mathrm{m}$. 

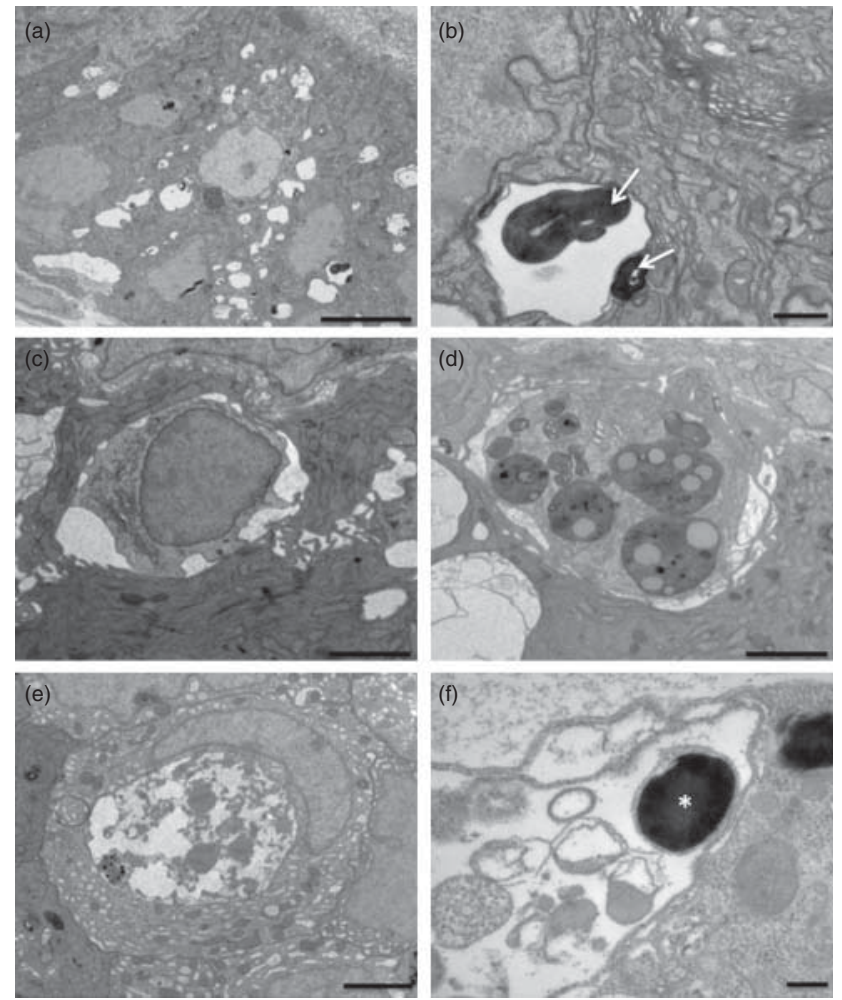

Figure 6 Phagosomes within the epididymal epithelium of the caput epididymis observed by transmission electron microscopy. (a) Epididymal epithelial cells show phagosomes containing immature germ cells at different stages of degradation, bar $=5 \mu \mathrm{m}$. (b) Magnification of a phagosome containing laminar structures (arrows) as a result of cell membrane digestion, bar $=500 \mathrm{~nm}$. (c) Phagosome containing an immature germ cell before degradation, bar $=2 \mu \mathrm{m}$. (d and e) Phagosomes showing different extents of immature germ cell digestion, $b a r=2 \mu \mathrm{m}$. (f) Phagosome showing remains of the nuclei of more mature spermatogenic cells $(*)$ bar $=500 \mathrm{~nm}$.

different epididymal regions. Phagosomes could be detected in all epididymal tubule sections within a zone of phagocytosis in the caput and corpus epididymis. However, epididymal tubule sections in the cauda epididymis showed no phagosomes. The size of the epididymal tubule sections varied according to each epididymal region, and the numbers of epithelial cells per tubule section were $51 \pm 2.901$ in the caput epididymis, $64.56 \pm 5.37$ in the corpus epididymis, and $101.67 \pm 12.76$ in the cauda epididymis. The intensity of phagocytosis diminished across the epididymal regions: the numbers of phagosomes observed per tubule section were $14.57 \pm 1.247$ in the caput epididymis, $5.71 \pm 0.70$ in the corpus epididymis, and $2.17 \pm 0.65$ in the cauda epididymis.

To confirm the contents of the phagosomes observed, sections were immunostained using the anti-GFP antibody. Engulfed bodies in the epididymal epithelium stained positive for EGFP, as well as the immature germ cells present in the epididymal lumen (Fig. 4a and b).

\section{Response of the prepuberal epididymis to the colchicine-induced massive release of immature germ cells}

To examine the response of the immature epididymis to the massive release of immature germ cells, colchicine was injected into the rete testis of prepuberal mice. Animals were then killed daily from 1 to 8 days after colchicine administration, and the epididymides were collected and examined by fluorescence stereoscopy. Intense fluorescence was observed from day 1 after colchicine administration in the caput epididymis. Immature germ cells advanced through the corpus epididymis until day 8 post-colchicine administration, when fluorescence was only observed at the extreme end of the cauda epididymis. No fluorescence was observed in non-injected epididymides. We then went on to examine the response of the epididymal epithelium to the release of immature germ cells by observing hematoxylin-stained epididymal sections by bright field microscopy. No signs of phagocytosis were observed in mice up to 30 days old (Fig. 2d). By contrast, phagocytosis was first observed in 31-day-old animals in the corpus epididymis 8 days after colchicine treatment, although sections revealed a reduced number of phagosomes relative to the numbers observed in epididymides from adult mice after colchicine administration.

\section{Discussion}

The Dazl gene is expressed in germ cells across different developmental stages. Its expression was initially described in B-spermatogonia, preleptotene, and zygotene spermatocytes and more intensely in pachytene spermatocytes (Ruggiu et al. 1997). However, it was later shown that Dazl persists in spermatids and even spermatozoa (Reijo et al. 2000, Rocchietti-March et al. 2000). Nicholas et al. (2009) described a transgenic mouse model in which Dazl-driven expression of EGFP was only detected from the pachytene spermatocyte to the elongating spermatid, and weak expression appeared in some spermatogonia. In this article, the authors mentioned non-uniform germ cell staining, as some tubule sections did not stain positive for EGFP and others exhibited partial staining. By contrast, in our transgenic mice, we observed uniform EGFP staining at all epithelial cycle stages of the seminiferous tubules, and expression continued from the spermatogonia to their maturation into spermatocytes, and round and elongating spermatids. These discrepancies may be attributed to the ESC injection instead of the pronuclear injection used to generate our transgenic mice and the fact that we selected the transformed ESC line showing the strongest expression of the reporter gene (GFP). Owing to this robust EGFP expression of the transgenic line used, we were able to easily identify immature germ cells through 
epididymal connective tissue walls and discriminate between mature and immature germ cells.

Mammalian spermatogenesis takes place in two stages. In prepuberal mice, a first round of spermatogenesis sequentially gives rise to all germ cell stages within the seminiferous tubules. The second stage consists of all subsequent rounds of spermatogenesis that constantly occur in adult animals to produce mature gametes (Rodriguez et al. 1997). We here observed that during the first stage of spermatogenesis, a wave of immature germ cells is released into the epididymis, but the immature epididymis is not able to react to this abnormal situation. At 35 days of age, spermatogenesis is complete and mature spermatozoa are released into the epididymis. However, we first detected immature germ cells in the epididymis at 18 days, which is when all germ cell types from spermatogonia to round spermatids occur in the testicular seminiferous tubules, although spermiogenesis has not yet started (Bellve et al. 1977). The ratio of different stages of germ cells to Sertoli cells remains relatively constant during spermatogenesis, and control of this ratio is probably a critical requirement during testis differentiation. It has been proposed that an excessive production of spermatogonia may require the subsequent death of some of these cells to maintain an optimal ratio (Allan et al. 1987). Moreover, a physiological early apoptotic wave among germ cells has been described during the first round of spermatogenesis in prepuberal mice (Rodriguez et al. 1997). This apoptosis is necessary for normal subsequent spermatogenesis, and apoptotic germ cells, while moving toward the basal lamina, are phagocytosed by Sertoli cells (Rodriguez et al. 1997). To the best of our knowledge, immature germ cell release during the first round of spermatogenesis has not been described elsewhere and could be another mechanism whereby an appropriate balance is maintained between the different stages of germ cells and Sertoli cells.

The role of the epididymis as a quality control organ in preventing infertile gametes entering the ejaculate via phagocytosis has been extensively investigated. Most early studies were conducted in induced pathological conditions such as blockage of the duct by experimental ligation (Hoffer et al. 1975, Cooper \& Hamilton 1977, Sinowatz et al. 1979). However, despite the observation of spermiophagy by the epididymal epithelium, this mechanism was ruled out as the main route of disposal of the massive amount of spermatozoa present in the epididymis in these conditions. In physiological conditions, it has been suggested that the epididymis achieves sperm quality control by defective sperm ubiquitination followed by phagocytosis by epithelial cells (Sutovsky et al. 2001). However, this hypothesis has been refuted as there is no evidence that under normal conditions the epididymis routinely absorbs significant numbers of defective sperm (Cooper et al. 2002, Jones 2004).
In physiological conditions, the presence of immature germ cells in adult epididymis is uncommon, so some authors induce the release of male germ cells from seminiferous tubules using microtubule disruptors (Correa et al. 2002, Quintar et al. 2011). In the rat, an in vivo model has been described in which the epididymis is exposed to an increasing number of immature germ cells (Quintar et al. 2011). In epididymides examined up to $72 \mathrm{~h}$ after microtubule disruptor administration, a greater presence of immature germ cells was observed in the lumen of the first epididymal segment, and numbers declined during their transit through the epididymal tract. A massive surge of phagocytosis was observed restricted to the epithelium of the initial segment of the epididymis $24 \mathrm{~h}$ after microtubule disruptor administration (Quintar et al. 2011). Using the same model but in mice, we were able to track immature germ cells over time until they abandoned the epididymis 6 days after colchicine administration, and phagocytosis was detected throughout the caput, corpus, and cauda epididymis, thereby not restricted to a given segment. Besides the different animal species, our observations differed from those of Quintar et al. Such differences could be attributable to the large numbers of immature germ cells in all epididymal regions detected in our model (as opposed to diminishing numbers during transit through the epididymal tract) determining that all segments of the epididymis were highly exposed to immature germ cells. Moreover, we detected phagosomes in regions where the main wave of fluorescence immature cells had passed on day 4 post-colchicine administration, while Quintar et al. only examined epididymides up to $72 \mathrm{~h}$ after the microtubule disruptor was administered.

Principal cells in the epididymal epithelium have secretory and absorption functions specific to each segment and also show modifications in their shape. Thus, a cell height reduction and width increase is observed distalwards from the caput to cauda epididymis, and microvilli also decrease distally in length (Abe et al. 1983). Similarly, we here observed differences in the phagocytic capacity of principal cells among distinct epididymal regions in our study. While small phagosomes in the caput epididymis contained ingested material at different degradation stages, consistent with observations by Quintar et al., phagosomes in the corpus and cauda epididymis were larger, even displacing cell organelles, and contained complete immature germ cells or appeared empty. Furthermore, more phagosomes were located in the caput epididymis than in corpus and cauda epididymis. Thus, the principal cells involved in phagocytosis in these latter regions could have a lower phagocytic efficiency than principal cells in the caput epididymis, perhaps determined by their difference in shape. We also observed that the prepuberal epididymis could not respond to the massive release of immature germ cells until animals were 
31 days of age, when small numbers of phagosomes appeared in some epididymal tubules within a zone of phagocytosis. Consequently, it could be that the absence of phagocytosis in prepuberal mice was attributable to the lack of maturity of the epididymis and that a capacity for phagocytosis is gradually acquired during epididymal development. However, in physiological conditions, the presence of immature germ cells in adult mature epididymis is an uncommon event, so this type of phagocytosis could be a sporadic event.

In conclusion, we observed that the different regions of the epididymis in adult mice are responsible for gamete quality control through the capacity of the epithelium to phagocytose immature germ cells from the epididymal lumen.

\section{Declaration of interest}

The authors declare that there is no conflict of interest that could be perceived as prejudicing the impartiality of the research reported.

\section{Funding}

This work was funded by grant AGL2012-39652-C02-01 from the Spanish Ministry of Science and Innovation. P Ramos-lbeas was supported by an FPI grant from the Spanish Ministry of Science and Innovation.

\section{References}

Abe K, Takano H \& Ito T 1983 Ultrastructure of the mouse epididymal duct with special reference to the regional differences of the principal cells. Archivum Histologicum Japonicum. Nippon Soshikigaku Kiroku $\mathbf{4 6}$ $51-68$.

Alexander NJ 1972 Vasectomy: long-term effects in the rhesus monkey. Journal of Reproduction and Fertility 31 399-406. (doi:10.1530/jrf.0. 0310399)

Allan DJ, Harmon B \& Kerr JFR 1987 Cell death in spermatogenesis. In Perspectives on Mammalian Cell Death, pp 229-258. Ed. CS Potten. Oxford: Oxford University Press.

Amann RP 1970 The male rabbit. IV. Quantitative testicular histology and comparisons between daily sperm production as determined histologically and daily sperm output. Fertility and Sterility 21 662-672.

Amann RP, Kavanaugh JF, Griel LC Jr \& Voglmayr JK 1974 Sperm production of Holstein bulls determined from testicular spermatid reserves, after cannulation of rete testis or vas deferens, and by daily ejaculation. Journal of Dairy Science 57 93-99. (doi:10.3168/jds.S00220302(74)84836-8)

Bellve AR, Cavicchia JC, Millette CF, O'Brien DA, Bhatnagar YM \& Dym M 1977 Spermatogenic cells of the prepuberal mouse. Isolation and morphological characterization. Journal of Cell Biology 74 68-85. (doi:10.1083/jcb.74.1.68)

Cooper TG \& Hamilton DW 1977 Phagocytosis of spermatozoa in the terminal region and gland of the vas deferens of the rat. American Journal of Anatomy 150 247-267. (doi:10.1002/aja.1001500204)

Cooper TG, Yeung CH, Jones R, Orgebin-Crist MC \& Robaire B 2002 Rebuttal of a role for the epididymis in sperm quality control by phagocytosis of defective sperm. Journal of Cell Science 115 5-7.

Correa LM, Nakai M, Strandgaard CS, Hess RA \& Miller MG 2002 Microtubules of the mouse testis exhibit differential sensitivity to the microtubule disruptors Carbendazim and colchicine. Toxicological Sciences 69 175-182.
Crabo B, Gustafsson B, Nicander L \& Rao AR 1971 Subnormal testicular function in a bull concealed by phagocytosis of abnormal spermatozoa in the efferent ductules. Journal of Reproduction and Fertility 26 393-396. (doi:10.1530/jrf.0.0260393)

Hoffer AP, Hamilton DW \& Fawcett DW 1975 Phagocytosis of spermatozoa by the epithelial cells of the ductuli efferentes after epididymal obstruction in the rat. Journal of Reproduction and Fertility 44 1-9. (doi:10.1530/jrf.0.0440001)

Jones R 2004 Sperm survival versus degradation in the mammalian epididymis: a hypothesis. Biology of Reproduction 71 1405-1411. (doi:10.1095/biolreprod.104.031252)

Miranda A, Pericuesta E, Ramirez MA \& Gutierrez-Adan A 2011 Prion protein expression regulates embryonic stem cell pluripotency and differentiation. PLoS ONE 6 e18422. (doi:10.1371/journal.pone.0018422)

Nicholas CR, Xu EY, Banani SF, Hammer RE, Hamra FK \& Reijo Pera RA 2009 Characterization of a Dazl-GFP germ cell-specific reporter. Genesis 47 74-84. (doi:10.1002/dvg.20460)

Paufler SK \& Foote RH 1969 Sperm retention and resorption in sexually active rabbits with epididymal ligatures. Proceedings of the Society for Experimental Biology and Medicine 131 1179-1183. (doi:10.3181/00379727-131-34065)

Pericuesta E, Ramirez MA, Villa-Diaz A, Relano-Gines A, Torres JM, Nieto M, Pintado B \& Gutierrez-Adan A 2006 The proximal promoter region of $\mathrm{mTert}$ is sufficient to regulate telomerase activity in ES cells and transgenic animals. Reproductive Biology and Endocrinology 45. (doi:10.1186/1477-7827-4-5)

Phadke AM 1964 Fate of spermatozoa in cases of obstructive azoospermia and after ligation of vas deferens in man. Journal of Reproduction and Fertility 7 1-12. (doi:10.1530/jrf.0.0070001)

Quintar AA, Nishioka S, Torres AI, Maldonado CA \& Aoki A 2011 The initial segment of the rat epididymis is able to uptake immature germ cells shed by testicular damage. Cells, Tissues, Organs 193 170-183. (doi:10.1159/000317127)

Ramirez MA, Pericuesta E, Fernandez-Gonzalez R, Moreira P, Pintado B \& Gutierrez-Adan A 2006 Transcriptional and post-transcriptional regulation of retrotransposons IAP and MuERV-L affect pluripotency of mice ES cells. Reproductive Biology and Endocrinology 455. (doi:10.1186/1477-7827-4-55)

Ramirez MA, Pericuesta E, Fernandez-Gonzalez R, Pintado B \& GutierrezAdan A 2007 Inadvertent presence of pluripotent cells in monolayers derived from differentiated embryoid bodies. International Journal of Developmental Biology 51 397-407. (doi:10.1387/ijdb.062255mr)

Ramirez MA, Fernandez-Gonzalez R, Perez-Crespo M, Pericuesta E \& Gutierrez-Adan A 2009 Effect of stem cell activation, culture media of manipulated embryos, and site of embryo transfer in the production of F0 embryonic stem cell mice. Biology of Reproduction 80 1216-1222. (doi:10.1095/biolreprod.108.075044)

Reijo RA, Dorfman DM, Slee R, Renshaw AA, Loughlin KR, Cooke H \& Page DC 2000 DAZ family proteins exist throughout male germ cell development and transit from nucleus to cytoplasm at meiosis in humans and mice. Biology of Reproduction 63 1490-1496. (doi:10.1095/ biolreprod63.5.1490)

Rocchietti-March M, Weinbauer GF, Page DC, Nieschlag E \& Gromoll J 2000 Dazl protein expression in adult rat testis is up-regulated at meiosis and not hormonally regulated. International Journal of Andrology 23 51-56. (doi:10.1046/j.1365-2605.2000.00207.x)

Rodriguez I, Ody C, Araki K, Garcia I \& Vassalli P 1997 An early and massive wave of germinal cell apoptosis is required for the development of functional spermatogenesis. EMBO Journal $\mathbf{1 6}$ 2262-2270. (doi:10.1093/emboj/16.9.2262)

Roussel JD, Stallcup OT \& Austin CR 1967 Selective phagocytosis of spermatozoa in the epididymis of bulls, rabbits, and monkeys. Fertility and Sterility 18 509-516.

Ruggiu M, Speed R, Taggart M, McKay SJ, Kilanowski F, Saunders P, Dorin J \& Cooke HJ 1997 The mouse Dazla gene encodes a cytoplasmic protein essential for gametogenesis. Nature 389 73-77. (doi:10.1038/37987)

Simone FA \& Young WC 1931 A study of the function of the epididymis: IV. The fate of non-ejaculated spermatozoa in the genital tract of the male guinea pig. Journal of Experimental Biology 8 163-175.

Sinowatz F, Wrobel KH, Sinowatz S \& Kugler P 1979 Ultrastructural evidence for phagocytosis of spermatozoa in the bovine rete testis and testicular straight tubules. Journal of Reproduction and Fertility 57 1-4. (doi:10.1530/jrf.0.0570001) 
Sutovsky P, Moreno R, Ramalho-Santos J, Dominko T, Thompson WE \& Schatten G 2001 A putative, ubiquitin-dependent mechanism for the recognition and elimination of defective spermatozoa in the mammalian epididymis. Journal of Cell Science 114 1665-1675.

Tingari MD \& Lake PE 1972 Ultrastructural evidence for resorption of spermatozoa and testicular fluid in the excurrent ducts of the testis of the domestic fowl, Gallus domesticus. Journal of Reproduction and Fertility 31 373-381. (doi:10.1530/jrf.0.0310373)

Turner TT, Bomgardner D, Jacobs JP \& Nguyen QA 2003 Association of segmentation of the epididymal interstitium with segmented tubule function in rats and mice. Reproduction 125 871-878. (doi:10.1530/rep. 0.1250871 )
Waldschmidt MK \& Kinzler HM 1964 Vorkonnmen von desoxyribonuklease in mänlichen geschlechtssekreten beim rind. Die Naturwissenschaften 51 364. (doi:10.1007/BF00637886)

Yen PH 2004 Putative biological functions of the DAZ family. International Journal of Andrology 27 125-129. (doi:10.1111/j.1365-2605.2004.00469.x)

Received 8 April 2013

First decision 20 May 2013

Revised manuscript received 26 July 2013

Accepted 28 August 2013 